\title{
Contraceptive use among migrant, second-generation migrant and non- migrant women seeking abortion care: a descriptive cross-sectional study conducted in Sweden
}

\author{
Karin Emtell Iwarsson, ${ }^{1}$ Elin C Larsson, ${ }^{1,2}$ Kristina Gemzell-Danielsson, ${ }^{1}$ \\ Birgitta Essén, ${ }^{2}$ Marie Klingberg-Allvin ${ }^{1,3}$
}

\begin{abstract}
- Additional material is published online only. To view please visit the journal online (http://dx.doi.org/10.1136/ bmjsrh-2018-200171).
\end{abstract}

For numbered affiliations see end of article.

\section{Correspondence to}

Karin Emtell Iwarsson,

Department of Women's and

Children's Health, Karolinska Institutet, WHO-Centre, QB:84, Karolinska University Hospital Solna, Stockholm 171 76,

Sweden; karin.emtell.iwarsson@ ki.se

$\mathrm{KEI}$ and $\mathrm{ECL}$ contributed equally.

Received 29 June 2018 Revised 19 December 2018 Accepted 27 December 2018 Published Online First 21 January 2019

\section{Check for updates}

(c) Author(s) (or their employer(s)) 2019. No commercial re-use. See rights and permissions. Published by BMJ.

\footnotetext{
To cite: Emtell Iwarsson K, Larsson EC, Gemzell-

Danielsson K, et al. BMJ Sex Reprod Health

2019;45:118-126.
}

\author{
ABSTRACT \\ Introduction The objective of this study was to \\ compare ever-in life contraception use, use of \\ contraception at current conception, and planned \\ use of contraception after an induced abortion, \\ among three groups of women: migrants, second- \\ generation migrants and non-migrant women, \\ and to compare the types of contraception \\ methods used and intended for future use among \\ the three groups of women. \\ Methods The cross-sectional study administered \\ a questionnaire face-to-face to women aged 18 \\ years and older who were seeking abortion care \\ at one of six abortion clinics in Stockholm County \\ from January to April 2015.

\section{Key messages} \\ - The overall use of contraception \\ historically, at conception, and planned \\ use after an induced abortion was lower \\ among migrants and second-generation \\ migrants. \\ - Historically, the use of pills and withdrawal \\ was higher among non-migrants and \\ the copper intrauterine device among \\ migrants. \\ - Planned use of long-acting reversible \\ contraception was higher among \\ migrants and second-generation \\ migrants.
}

Results The analysis included 637 women. Migrants and second-generation migrants were less likely to have used contraception historically, at the time of the current conception, and to plan to use contraception after their induced abortion compared with non-migrant women. Historically, non-migrants had used pills (89\%) and withdrawal (24\%) while migrants had used the copper intrauterine device (24\%) to a higher extent compared to the other two groups of women. Both the migrants (65\%) and second-generation migrants $(61 \%)$ were more likely than the nonmigrants (48\%) to be planning to use long-acting reversible contraception.

Conclusions Lower proportions of contraception use were found in migrants and secondgeneration migrants than in non-migrants. In addition, there were significant differences in the types of contraception methods used historically and intended for future use.

\section{INTRODUCTION}

In both western Europe and the USA, migrant women have a higher frequency of induced abortion than do the majority of the female population. ${ }^{1-4}$ Previous research from Sweden has also found that migrant women, including adolescents, are more likely to have an induced abortion than are Swedish-born women, ${ }^{5}$ and that migrants had less experience using contraceptives than Swedish-born women. ${ }^{6}$

In Sweden, 35 000-38000 induced abortions are performed annually, translating into an abortion rate of 20.8 per 1000 women of reproductive age, which is higher than in other western European countries. ${ }^{7}$ Women aged $20-29$ years have the highest rate of induced abortion in Sweden ${ }^{7}$ and Stockholm County is one of three counties that have the highest abortion rates. ${ }^{8}$ Swedish legislation states that all women regardless of citizenship should be able to have an induced abortion on request up to 18 weeks of gestation. 
The reasons suggested for higher frequencies of induced abortion include language barriers, lack of knowledge regarding contraception, limited access to contraception or information about contraception, ambivalence regarding sexuality, factors related to relationships with partners, and uncertain living conditions. ${ }^{12}$ Multiple factors determine contraceptive uptake and use, and easy access, good counselling and the availability of effective, acceptable methods are prerequisites to preventing unintended pregnancies in general. ${ }^{69}$

In Sweden, contraception counselling is free of charge for all women. In the area of study, copper intrauterine devices (IUDs) are free of charge. Hormonal contraception methods such as the patch, vaginal ring, injection, intrauterine system (IUS), implant and most hormonal pills are partially subsidised for women under the age of 26 years and may even be free of charge for women aged under 21 years, depending on their region of residence. The unmet need for contraception has been estimated as being 9\% among all Swedish women and 13\% among Swedish women aged 21-30 years. ${ }^{10}$ However, women who did not understand Swedish were not included in the study. ${ }^{10}$ Among women who used a method of contraception, 24\% used long-acting reversible contraception (LARC), including copper IUDs, the levonorgestrel-releasing IUS or a subdermal contraceptive implant. ${ }^{10}$ LARC methods are highly effective and reduce the risk of contraceptive failure, unintended pregnancy, and both first and repeat induced abortions when compared with other methods, including pills, patches, vaginal rings and injections. ${ }^{11-13}$

The United Nations' Sustainable Development Goals state that by 2030 all women should have rights and access to sexual and reproductive healthcare, including contraception. ${ }^{14}$ One goal of Sweden's public health policy is to achieve equal healthcare for the entire population. ${ }^{15}$

Achieving these global and national goals requires increased knowledge of migrant women's contraception use today, especially since migrant women have a higher risk of repeated abortions. ${ }^{6}$

Consequently, the current study sought to compare the methods of contraception used by migrant, second-generation migrant and non-migrant women. Specifically, the study identified the methods used historically and at conception and the methods intended for use after induced abortion among these three groups of women.

\section{METHODS}

\section{Study design and population}

The study used a cross-sectional design, which was applied using a questionnaire administered during a face-to-face interview with the midwife at the abortion clinic. The study was conducted at six abortion clinics in Stockholm County, Sweden that collectively account for approximately $55 \%$ of all abortions in the county. The study used consecutive enrolment, and data collection took place from January to April 2015. The eligible women were at least 18 years old and had sought and decided to have an induced abortion. The outcome measures were: i) the historical use of contraception and the methods used, ii) the method used at conception, and iii) the methods intended for use after the abortion. The study included both migrant and second-generation migrants and non-migrants. Migrants was defined as born abroad while second-generation migrant status was defined as having been born in Sweden to two parents who were born abroad. ${ }^{16}$ Adopted women were defined as non-migrants if they were born abroad to one or two parents who were born in Sweden. Figure 1 outlines the sampling procedure.

\section{Data collection}

Each interview took place after the woman's first appointment at the abortion clinic. If the woman gave her consent, the healthcare provider conducted a face-to-face interview to allow the women to answer the questionnaire. The same healthcare provider also provided contraceptive counselling, and prescribed and inserted, if needed, contraceptives after the abortion. The questionnaire contained questions related to sociodemographic background and experiences with and planned use of contraception. The majority of the questions had been used in a previous Swedish study. ${ }^{9}$ Before the study commenced, the questionnaire was pilot tested on six women: three migrants, one second-generation migrant and two non-migrants. Two professional interpreters were used. The pilot test did not lead to any changes in the questionnaire. The written information used in the study was translated into the seven languages most commonly used by patients at the clinics, and a professional interpreter was used when needed. Ethical clearance for the study was obtained from the regional ethics committee in Stockholm (Dnr 2014/1191-31/5).

\section{Data analysis}

The data were analysed using SPSS Statistics version 23. The researchers assumed that $20 \%$ of the women seeking abortions would be migrant and that the differences in the historical use of contraceptives between migrants and non-migrants would be 10\%. These assumptions are based on data from a previous study. ${ }^{6}$ To achieve a power of $80 \%$, the researchers aimed to recruit 1300 women. However, the study was only able to include 637 participants (figure 1). Fisher's exact test, for some calculations obtained through a Monte Carlo simulation, and Chi-square tests were used to compare the sociodemographic characteristics, contraception use and contraception methods of the migrants, second-generation migrants and 


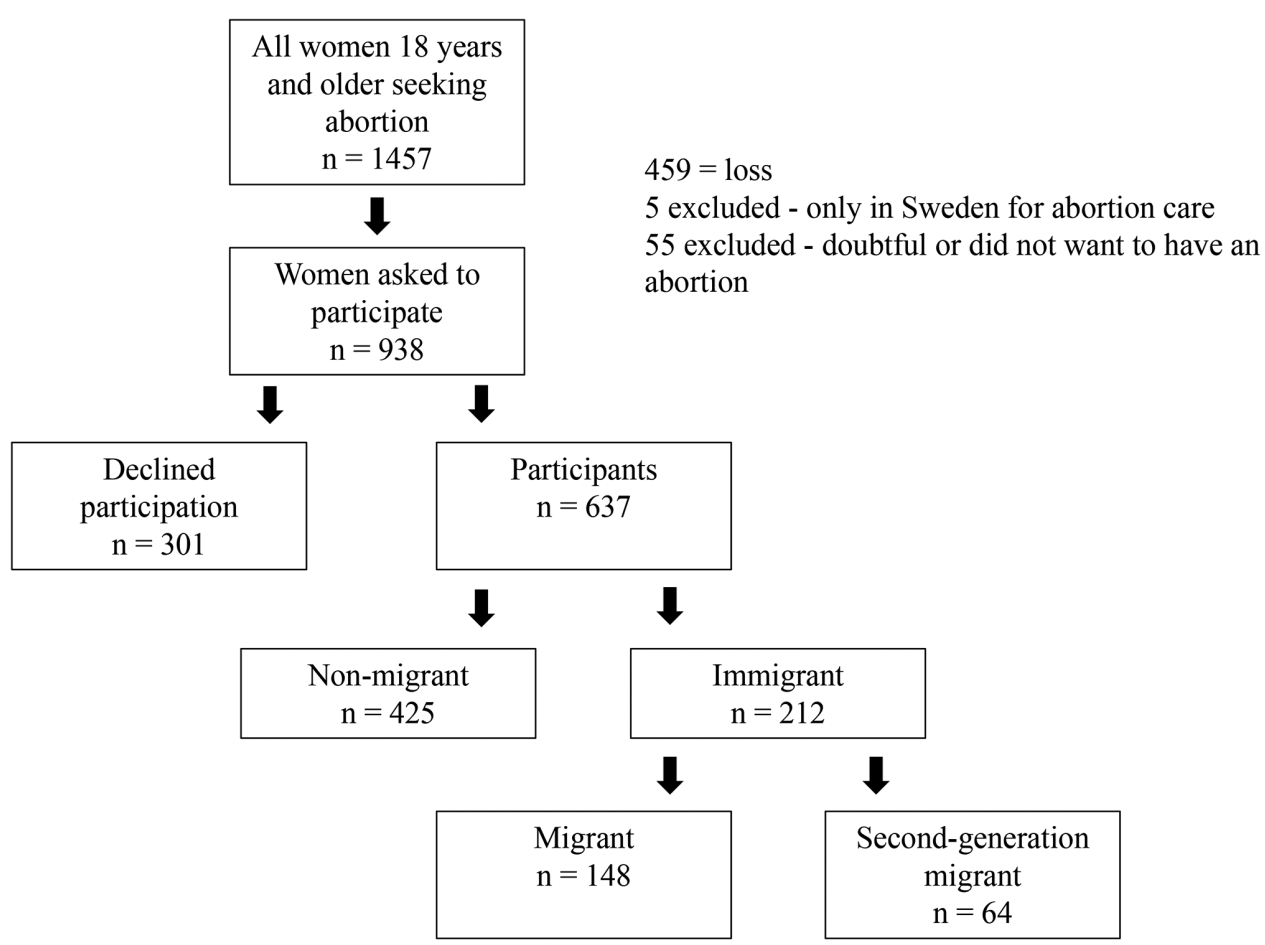

Figure 1 Flowchart of eligible, enrolled women and the final study population.

non-migrants. A $p$ value of less than 0.05 was considered statistically significant.

\section{Patient and public involvement}

Patients were not involved.

\section{RESULTS}

\section{Study population}

During the study period, 1457 women sought abortion care at the clinics. Of these, 459 were not asked to participate in the study, five were excluded because they were in Sweden only for abortion care and 55 were excluded because they expressed doubt that they would have an abortion or had decided not to have one. Of the 938 women who were invited to participate, 637 agreed, of which $67 \%$ were non-migrants, $23 \%$ were migrants and $10 \%$ were second-generation migrants (figure 1).

Differences in sociodemographic characteristics were observed, and among migrants, the largest age group was 30-34 years, while the non-migrants and second-generation migrants were younger (table 1). The migrants were more likely to have children than the women in the other two groups. In all three groups, the majority had a secondary school education and were employed at the time of the survey (table 1).

\section{Sexuality education and contraception counselling}

The migrants were less likely to have received any sexuality education in schools (63\%) than the non-migrants (98\%) and the second-generation migrants (94\%) (online supplementary tables). The migrants also were less likely to have received contraception counselling
(87\%) compared with the non-migrants (99\%) and second-generation migrants (97\%) (online supplementary tables). Of those who had received contraception counselling, the migrants were more likely $(48 \%)$ to have received it from midwives at primary healthcare clinics in Sweden, and the majority of the non-migrants $(73 \%)$ and second-generation migrants (60\%) had received it at youth clinics. The migrants were more likely to state that they did not have sufficient knowledge to choose a method of contraception to use after their abortion (19\%); only $10 \%$ of non-migrants and $13 \%$ of second-generation migrants gave these responses.

\section{Previous contraceptive use}

In total, $96 \%$ of the respondents had used contraception at some point in their lives, but there were significant differences between the three groups, with non-migrants reporting the highest use (99\%), second-generation migrants reporting the secondhighest use (95\%) and migrants reporting the lowest use $(89 \%)$. In all groups, the most common contraception methods used were oral contraceptives, which were used by a significantly higher proportion of non-migrants (89\%) than migrants (63\%) and second-generation migrants $(80 \%)$. The migrants were significantly more likely to have used copper IUDs $(24 \%)$ than second-generation migrants $(10 \%)$ and non-migrants $(17 \%)$. In each group, about one-third stated that they had ever used LARC contraceptive methods (table $2 \mathrm{~A}$ ). 
Table 1 Sociodemographic characteristics of non-migrant, migrant and second-generation migrant women seeking abortion care in Stockholm County

\begin{tabular}{|c|c|c|c|c|c|}
\hline Characteristic & $\begin{array}{l}\text { Non-migrant } \\
(\mathrm{n}(\%))\end{array}$ & $\begin{array}{l}\text { Migrant } \\
(\mathrm{n}(\%))\end{array}$ & $\begin{array}{l}\text { Second- } \\
\text { generation } \\
\text { migrant (n (\%)) }\end{array}$ & $\begin{array}{l}\text { Total } \\
(\mathrm{n}(\%))\end{array}$ & $P$ value \\
\hline Age (years) & & & & & $0.004^{*}$ \\
\hline $18-19$ & $12(2.8)$ & $3(2.0)$ & $2(3.2)$ & $17(2.7)$ & \\
\hline $20-24$ & $129(30.4)$ & $22(14.9)$ & $22(34.9)$ & $173(27.2)$ & \\
\hline $25-29$ & $105(24.7)$ & $34(23.0)$ & $18(28.6)$ & $157(24.7)$ & \\
\hline $30-34$ & $79(18.6)$ & $41(27.7)$ & $11(17.5)$ & $131(20.6)$ & \\
\hline $35-39$ & $52(12.2)$ & $30(20.3)$ & $6(9.5)$ & $88(13.8)$ & \\
\hline $40-49$ & $48(11.3)$ & $18(12.2)$ & $4(6.3)$ & $70(11.0)$ & \\
\hline Highest completed level of education & & & & & $0.389+$ \\
\hline Primary school or equivalent & $38(9.1)$ & $22(15.1)$ & $7(11.7)$ & $67(10.8)$ & \\
\hline Secondary school & $233(55.9)$ & $70(47.9)$ & $33(55.0)$ & $336(53.9)$ & \\
\hline College/university & $136(32.6)$ & $50(34.2)$ & $20(33.3)$ & $206(33.1)$ & \\
\hline Other & $10(2.4)$ & $4(2.7)$ & $0(0.0)$ & $14(2.2)$ & \\
\hline Occupation & & & & & $0.001^{*}$ \\
\hline Student SFI & $0(0.0)$ & $8(5.4)$ & $0(0.0)$ & $8(1.3)$ & \\
\hline Student (not SFI $\ddagger)$ & $82(19.4)$ & $32(21.8)$ & $13(20.3)$ & $127(20.0)$ & \\
\hline Sick leave & $10(2.4)$ & $0(0.0)$ & $0(0.0)$ & $10(1.6)$ & \\
\hline Early retirement pension & $0(0.0)$ & $0(0.0)$ & $1(1.6)$ & $1(0.2)$ & \\
\hline Employed & $303(71.6)$ & $92(62.6)$ & $44(68.8)$ & $439(69.2)$ & \\
\hline Maternity leave & $33(7.8)$ & $14(9.5)$ & $10(15.6)$ & $57(9.0)$ & \\
\hline Jobseeker & $25(5.9)$ & $10(6.8)$ & $4(6.3)$ & $39(6.2)$ & \\
\hline Other & $1(0.2)$ & $3(2.0)$ & $0(0.0)$ & $4(0.6)$ & \\
\hline Relationship & & & & & $0.005^{*}$ \\
\hline Single & $73(17.3)$ & $24(16.2)$ & $12(18.8)$ & $109(17.2)$ & \\
\hline Married or living with partner & $236(55.9)$ & $90(60.8)$ & $31(48.4)$ & $357(56.3)$ & \\
\hline Not living with partner & $104(24.6)$ & $29(19.6)$ & $20(31.3)$ & $153(24.1)$ & \\
\hline Other§ & $9(2.1)$ & $5(3.4)$ & $1(1.6)$ & $15(2.4)$ & \\
\hline Number of (living) children & & & & & $0.040^{*}$ \\
\hline 0 & $235(56.0)$ & $58(40.0)$ & $33(52.4)$ & $326(51.9)$ & \\
\hline 1 & $55(13.1)$ & $25(17.2)$ & $12(19.0)$ & $92(14.6)$ & \\
\hline 2 & $90(21.4)$ & $38(26.2)$ & $11(17.5)$ & $139(22.1)$ & \\
\hline 3 & $30(7.1)$ & $18(12.4)$ & $7(11.1)$ & $55(8.8)$ & \\
\hline 4 & $5(1.2)$ & $5(3.4)$ & $0(0.0)$ & $10(1.6)$ & \\
\hline $5+$ & $5(1.2)$ & $1(0.8)$ & $0(0.0)$ & $6(1.0)$ & \\
\hline \multicolumn{6}{|l|}{ Time in Sweden (years) } \\
\hline$<1$ & & $10(6.9)$ & & & \\
\hline $1-5$ & & $24(16.6)$ & & & \\
\hline $6-10$ & & $38(26.2)$ & & & \\
\hline$>10$ & & $73(50.3)$ & & & \\
\hline Religion & & & & & $<0.001^{*}$ \\
\hline No religion & $203(47.8)$ & $27(18.5)$ & $18(28.1)$ & $248(39.1)$ & \\
\hline Islam & $3(0.7)$ & $50(34.2)$ & $12(18.8)$ & $65(10.2)$ & \\
\hline Christian Catholic & $4(0.9)$ & $32(21.9)$ & $12(18.8)$ & $48(7.6)$ & \\
\hline Christian Protestant & $210(49.4)$ & $15(10.3)$ & $10(15.6)$ & $235(37.0)$ & \\
\hline
\end{tabular}




\begin{tabular}{|c|c|c|c|c|c|}
\hline Characteristic & $\begin{array}{l}\text { Non-migrant } \\
\text { (n (\%)) }\end{array}$ & $\begin{array}{l}\text { Migrant } \\
\text { (n (\%)) }\end{array}$ & $\begin{array}{l}\text { Second- } \\
\text { generation } \\
\text { migrant (n (\%)) }\end{array}$ & $\begin{array}{l}\text { Total } \\
\text { (n (\%)) }\end{array}$ & $P$ value \\
\hline Christian Orthodox & $3(0.7)$ & $13(8.9)$ & $11(17.2)$ & $27(4.3)$ & \\
\hline Buddhism & $0(0.0)$ & $3(2.1)$ & $0(0.0)$ & $3(0.5)$ & \\
\hline Hinduism & $0(0.0)$ & $0(0.0)$ & $1(1.6)$ & $1(0.2)$ & \\
\hline Judaism & $0(0.0)$ & $0(0.0)$ & $0(0.0)$ & $0(0.0)$ & \\
\hline Other & $2(0.5)$ & $6(4.1)$ & $0(0.0)$ & $8(1.3)$ & \\
\hline \multicolumn{6}{|c|}{ Region of origin for foreign-born women } \\
\hline Eastern Mediterranean & & $56(37.8)$ & & & \\
\hline Europe & & $42(28.4)$ & & & \\
\hline Africa & & $22(14.9)$ & & & \\
\hline South America & & $18(12.2)$ & & & \\
\hline Southeast Asia & & $4(2.7)$ & & & \\
\hline Western Pacific & & $6(4.1)$ & & & \\
\hline
\end{tabular}

*Fischer's exact test obtained through a Monte Carlo simulation.

tFischer's exact test.

¥Swedish for migrants (SFI).

$\S$ The relationship grouped as 'other' included, for example, unclear relationship.

\section{Contraceptive use at conception}

At the time of conception, $32 \%$ had used a contraception method. Non-migrants used contraceptives at conception to a higher extent (34\%) compared to migrants $(25 \%)$ and second-generation migrants (30\%), indicating the highest contraceptive failure among non-migrants (online supplementary tables). The most common methods in all three groups were condoms (38\%) and pills (24\%). There were no significance differences between the methods used at conception (table 2B). The most frequently stated reasons for contraceptive failure were lack of compliance $(24 \%)$ and condom failure (22\%). The migrants were more likely to report miscalculation of days $(20 \%)$ as a reason for the failure than were non-migrants $(10 \%)$ and second-generation migrants (11\%) (online supplementary tables).

\section{Intended future use of contraception}

Of all the women, 93\% planned to use contraception after their induced abortion. Among women aged 20-24 years, the percentage rose to $98 \%$, and for

\begin{tabular}{|c|c|c|c|c|c|}
\hline $\begin{array}{l}\text { Contraceptive } \\
\text { method }\end{array}$ & $\begin{array}{l}\text { Non-migrant } \\
(\mathrm{n}(\%))\end{array}$ & $\begin{array}{l}\text { Migrant } \\
\text { (n (\%)) }\end{array}$ & $\begin{array}{l}\text { Second-generation } \\
\text { (n (\%)) }\end{array}$ & $\begin{array}{l}\text { Total } \\
\text { (n (\%)) }\end{array}$ & $P$ value \\
\hline Pills & $374(89.0)$ & $83(63.4)$ & $49(80.3)$ & $506(82.7)$ & $<0.001$ \\
\hline Condoms & $230(54.8)$ & 65 (49.6) & $29(47.5)$ & 324 (52.9) & 0.396 \\
\hline Withdrawal & $99(23.6)$ & $16(12.2)$ & $8(13.1)$ & $123(20.1)$ & 0.006 \\
\hline Copper IUD & $70(16.7)$ & $31(23.7)$ & $6(9.8)$ & 107 (17.5) & 0.047 \\
\hline Implant & $60(14.3)$ & $18(13.7)$ & $14(23.0)$ & $92(15.0)$ & 0.187 \\
\hline Vaginal ring & $67(16.0)$ & $13(9.9)$ & $10(16.4)$ & $90(14.7)$ & 0.218 \\
\hline Rhythm method & $62(14.8)$ & $14(10.7)$ & $7(11.5)$ & $83(13.6)$ & 0.435 \\
\hline Hormonal IUS & $34(8.1)$ & $7(5.3)$ & $4(6.6)$ & $45(7.4)$ & $0.587^{*}$ \\
\hline Patch & $16(3.8)$ & $2(1.5)$ & $1(1.6)$ & $19(3.1)$ & $0.460^{*}$ \\
\hline Injection & $12(2.9)$ & $3(2.3)$ & $2(3.3)$ & $17(2.8)$ & $0.857^{*}$ \\
\hline Other† & $18(4.3)$ & $7(5.3)$ & $3(4.9)$ & $28(4.6)$ & \\
\hline LARC $\neq$ & $135(31.8)$ & 46 (31.1) & $23(35.9)$ & $204(32.0)$ & 0.770 \\
\hline
\end{tabular}

*Fischer's exact test.

TThe methods grouped as 'other' included, for example, lactational amenorrhea, diaphragms and emergency contraceptive pills. ¥LARC=IUD/IUS and implant.

IUD, intrauterine device; IUS, intrauterine system; LARC, long-acting reversible contraception. 
Table 2B Contraceptive method used at time of current conception by non-migrant, migrant and second-generation migrant women seeking abortion care in Stockholm County

\begin{tabular}{lccccl}
\hline $\begin{array}{l}\text { Contraceptive } \\
\text { method }\end{array}$ & $\begin{array}{l}\text { Non- immigrant } \\
(\mathbf{n}(\%))\end{array}$ & $\begin{array}{l}\text { Foreign-born } \\
(\mathbf{n}(\%))\end{array}$ & $\begin{array}{l}\text { Second-generation(n } \\
(\%))\end{array}$ & $\begin{array}{l}\text { Total } \\
(\mathbf{n}(\%))\end{array}$ & P value \\
\hline Condom & $51(34.9)$ & $16(43.2)$ & $9(47.4)$ & $76(37.6)$ & 0.424 \\
\hline Pills & $37(25.3)$ & $7(18.9)$ & $5(26.3)$ & $49(24.3)$ & $0.769^{*}$ \\
\hline Rhythm method & $18(12.3)$ & $7(18.9)$ & $1(5.3)$ & $26(12.9)$ & $0.366^{*}$ \\
\hline Withdrawal & $14(9.6)$ & $3(8.1)$ & $0(0.0)$ & $17(8.4)$ & $0.576^{*}$ \\
\hline Vaginal ring & $8(5.5)$ & $3(8.1)$ & $2(10.5)$ & $13(6.4)$ & $0.450^{*}$ \\
\hline Copper IUD & $2(1.4)$ & $0(0.0)$ & $0(0.0)$ & $2(1.0)$ & $1.000^{*}$ \\
\hline Hormonal IUS & $0(0.0)$ & $0(0.0)$ & $1(5.3)$ & $1(0.5)$ & $0.094^{*}$ \\
\hline Patch & $1(0.7)$ & $0(0.0)$ & $0(0.0)$ & $1(0.5)$ & $1.000^{*}$ \\
\hline Othert & $11(7.5)$ & $1(2.7)$ & $1(5.3)$ & $13(2.1)$ & \\
\hline LARC $\neq$ & $2(0.5)$ & $0(0.0)$ & $1(1.6)$ & $3(0.5)$ & $0.393^{*}$ \\
\hline
\end{tabular}

*Fischer's exact test.

†The methods grouped as 'other' included, for example, emergency contraceptive pills.

fLARC $=$ IUD/IUS and implant.

IUD, intrauterine device; IUS, intrauterine system; LARC, long-acting reversible contraception.

women aged 25-29 years it fell to 92\%. In particular, second-generation migrants aged 25-29 years were less likely $(78 \%)$ to be planning to use contraception after their abortion than women in either of the other two groups. The most common contraception method chosen by both the migrants and second-generation migrants was a hormonal IUS, and among non-migrants it was pills (table 3 ).

\section{Important factors in choosing a contraceptive}

For all women, the most important factor when choosing the method to use after abortion was that it did not have side effects (31\%). Using a long-acting contraceptive was also more important to migrants (12\%) than to non-migrants (8\%) and second-generation migrants (9\%) (online supplementary tables). Low-dose or hormonefree methods were mentioned as a factor by $19 \%$ of second-generation migrants, $18 \%$ of non-migrants and $11 \%$ of migrants. In addition, non-migrants (13\%) were more likely to state that amenorrhea, or the cessation of regular bleeding, was an important factor than were migrants $(7 \%)$ and second-generation migrants (4\%). No participants stated cost as a factor in whether they planned to use a specific contraception method after their abortion (online supplementary tables).

\begin{tabular}{|c|c|c|c|c|c|}
\hline $\begin{array}{l}\text { Type of contraceptive } \\
\text { method }\end{array}$ & $\begin{array}{l}\text { Non-migrant } \\
\text { (n (\%)) }\end{array}$ & $\begin{array}{l}\text { Migrant } \\
(\mathrm{n}(\%))\end{array}$ & $\begin{array}{l}\text { Second-generation } \\
\text { (n (\%)) }\end{array}$ & $\begin{array}{l}\text { Total } \\
\text { (n (\%)) }\end{array}$ & $P$ value \\
\hline Hormonal IUS & $111(27.6)$ & $40(30.3)$ & $18(31.0)$ & $169(28.5)$ & 0.760 \\
\hline Pills & $113(28.1)$ & $30(22.7)$ & $9(15.5)$ & $152(25.7)$ & 0.083 \\
\hline Copper IUD & $51(12.7)$ & $29(22.0)$ & $8(13.8)$ & $88(14.9)$ & 0.033 \\
\hline Implant & $26(6.5)$ & $14(10.6)$ & $9(15.5)$ & $49(8.3)$ & $0.036^{*}$ \\
\hline Vaginal ring & $34(8.5)$ & $2(1.5)$ & $4(6.9)$ & $40(6.8)$ & $0.012^{*}$ \\
\hline Condoms & $31(7.7)$ & $6(4.5)$ & $3(5.2)$ & $40(6.8)$ & $0.482^{*}$ \\
\hline Patch & $5(1.2)$ & $1(0.8)$ & $0(0.0)$ & $6(1.0)$ & $1.000^{*}$ \\
\hline Rhythm method & $2(0.5)$ & $1(0.8)$ & $0(0.0)$ & $3(0.5)$ & $0.688^{*}$ \\
\hline Withdrawal & $0(0.0)$ & $1(0.8)$ & $0(0.0)$ & $1(0.2)$ & $0.321^{*}$ \\
\hline Injection & $0(0.0)$ & $1(0.8)$ & $0(0.0)$ & $1(0.2)$ & $0.321^{*}$ \\
\hline Othert & $26(6.5)$ & $6(4.5)$ & $6(10.3)$ & $38(6.4)$ & \\
\hline LARC $\ddagger$ & 193 (48.4) & $85(64.9)$ & $35(61.4)$ & $313(53.3)$ & 0.002 \\
\hline
\end{tabular}

*Fischer's exact test.

†The methods grouped as 'other' included, for example, unspecified types of IUDs.

¥LARC=IUD/IUS and implant.

IUD, intrauterine device; IUS, intrauterine system; LARC, long-acting reversible contraception. 
For all groups, the proportion who had previously used LARC (32\%) was significantly lower than the proportion who planned to use it after their abortion $(53 \%)$. In particular, the proportions of both migrants $(65 \%)$ and second-generation migrants (61\%) who planned to use LARC were significantly higher than the proportion of non-migrants $(48 \%)$ who intended to use it. Non-migrants aged 20-24 years were the least likely (42\%) to report planning to use LARC after their abortion.

\section{Partner involvement in contraception decisions}

In all three groups, slightly less than one-third of the women reported that their partner was involved in the decision about using contraception after the abortion. The non-migrants were more likely to state that their partner wanted them to use contraception after the abortion (86\%) than were the migrants (73\%) and second-generation migrants $(82 \%)$. Furthermore, the migrants were more likely to state that they did not know if their partner wanted them to use contraception (22\%) than were non-migrants (10\%) and second-generation migrants (10\%).

\section{DISCUSSION \\ Main findings}

Among women seeking abortion care, both migrants and second-generation migrants were less likely ever to have used contraception previously than were non-migrants. These three groups of women also differed as regards the types of contraception methods they had used previously. Interestingly, the results indicated that migrants and second-generation migrants were more likely than non-migrants to be planning to use a LARC method after their abortions.

\section{Findings in context}

At the time of the current conception the migrants and second-generation migrants were less likely to have been using any method of contraception, while the non-migrants were more likely to have experienced failure of the contraception method they were using. Earlier research have pointed out the importance of improved counselling and access to LARC methods for nulliparous and young women, given the current low uptake of LARC among these groups. ${ }^{17}$ Structured contraception counselling can support women during their decision-making process and can increase the acceptance, selection and use of a contraception method, as well as adherence to it. ${ }^{18} 19$ The Contraceptive Health Research of Informed Choice Experience (CHOICE) method of contraception counselling has been shown to be effective for both short- and long-acting reversible forms of combined hormonal contraceptives and has been shown to both influence the method chosen and improve adherence to it. ${ }^{1120-22}$ Studies that have evaluated the CHOICE method have found increased uptake of LARC and higher patient satisfaction with LARC methods compared with shortacting methods. ${ }^{23} 24$ LARC use among Swedish women aged $16-49$ years is reported to be $24 \% .^{10}$ In the present study, non-migrants aged 20-24 years were less likely to report planning to use LARC after their abortion. Despite this, in this study the planned use of LARC increased by more than $20 \%$ in all age groups under 30 years compared with the historical use of LARC. Choosing a LARC method is in line with Sweden's recommendations for contraceptive use. ${ }^{25}$

The findings of the present study indicate that preand post-abortion contraception counselling must be person-centred in order to acknowledge the womens' needs. We found that migrants were more likely to state that they did not have sufficient knowledge to choose a contraception method after their abortion and that only $63 \%$ of the migrants had received sexuality education in schools. These findings are in agreement with the experience of abortion-care providers who have recounted their challenges in finding adequate time in which to provide sufficient counselling. ${ }^{26}$ From a public health perspective, it is important to increase both women's and men's access to person-centred information and shared decision-making. ${ }^{27}$ In Sweden, contraception counselling usually takes place in a one-on-one meeting, which may be a challenge for migrants from societies that are more collectivist. ${ }^{28}$ One potential approach to both increasing contraception use and decreasing unintended pregnancies may be to include both women and men in contraception counselling. ${ }^{29}$ Healthcare providers who counsel migrants have reported that cost and the presence or absence of regular bleeding are two important factors in their choice of contraception methods. ${ }^{30}$ However, the present study did not observe this among migrant and second-generation migrant women. Sweden's national public health goal is to make the social conditions necessary for good health available to the entire population on equal terms. To do this, it is very important to be aware of health differences in the population, such as, for example, people with foreign backgrounds. ${ }^{31}$

\section{Strength and limitations}

A strength of the present study is its intention to include all women who were seeking abortion care, including those from various ethnic backgrounds. Previous studies have excluded migrants due to language barriers. The proportion of women never asked to participate in the study could be explained by a high workload at the clinics according to the healthcare providers. However, some midwives mention that due to language barriers, which made the encounters longer, migrants who did not speak Swedish might have been asked to participate to a lower extent. Consequently, there might have been more women from the migrant groups that were lost. It might be that those who were lost or who refused to participate 
used contraceptives at a lower rate than those who did participate, and that therefore although this might not have changed the results significantly, the 'true' use of contraceptives might actually be lower than that indicated by the present study. Some of the measured variables that were not significant might have been if the study had reached the intended sample size. We have compared contraceptive use among abortion-seeking women, and contrasted the use between the three groups. Consequently, we cannot say whether or not the observed differences are also valid had we compared contraceptive use among the three groups among women who had not sought abortion care. The participating clinics are the largest abortion clinics in Stockholm County and are geographically distributed in the whole county. All women in Stockholm County, regardless of their residence, could visit any of the clinics, therefore we do not believe the sample would be different even if there were more participating clinics. However, this was not a population-based study and selection bias cannot be ascertained. Due to the small number of women in the different groups within the study, we could not make stratifications of sociodemographic characteristics. This would have been interesting in a larger sample to strengthen the study's validity.

\section{CONCLUSIONS}

In order to provide equitable, person-centred care, pre-abortion contraception counselling must recognise that knowledge and motives differ among women. Both migrants and second-generation migrants seem to have less knowledge of contraception and to be less likely to use a contraception method, and this should be taken into consideration when counselling these women. In addition, LARC uptake among non-migrants can be improved. The clinics offering comprehensive abortion care have an important role in contraception counselling for all women.

\section{Author affiliations \\ 'Department of Women's and Children's Health, Karolinska Institutet, WHO- Centre, QB:84, Karolinska University Hospital Solna, Stockholm, Sweden ${ }^{2}$ Department of Women's and Children's Health/International Maternal and Child Health (IMCH), Uppsala University, Akademiska Hospital, Uppsala, Sweden \\ ${ }^{3}$ School of Education, Health and Social Studies, Dalarna University, Falun, Sweden}

Correction notice Since this paper was first published online, a duplicate reference 25 has been deleted and a line from the supplementary file title has been removed.

Acknowledgements The authors would like to thank all who contributed to this study, especially the women, the providers and the abortion clinics. They would also like to thank Gaetano Marrone for his assistance with statistical analysis and Sebastian Emtell for entering the data.

Contributors KEI designed and implemented the study at the clinics, collected the data, cleaned and analysed the data and wrote the manuscript. ECL designed and implemented the study at the clinics, collected the data, cleaned and analysed the data and wrote the manuscript. KG-D secured the funding and revised the draft paper. $\mathrm{BE}$ secured the funding, designed the study and revised the draft paper. MK-A secured the funding, designed the study and revised the draft paper.

Funding This work was supported by FORTE Dnr 2013-2025 and FORTE Dnr 2016-01063.

Competing interests Dr. Emtell Iwarsson reports non-financial support from Bayer AB, non-financial support from RemovAid AS, outside the submitted work; Dr. Larsson has nothing to disclose. Dr. Gemzell-Danielsson reports personal fees from Bayer Ag, MSD/Merck, Exeltis, Gedeon Richter, Actavis, Ferring, HRA-Pharma, Exelgyn, SunPharma, Natural Cycles, outside the submitted work; Dr. Essén has nothing to disclose. Dr. Klingberg-Allvin has nothing to disclose.

Patient consent Not required.

Provenance and peer review Not commissioned; externally peer reviewed.

\section{REFERENCES}

1 Sedgh G, Singh S, Henshaw SK, et al. Legal abortion worldwide in 2008: levels and recent trends. Perspect Sex Reprod Health 2011;43:188-98.

2 Rademakers J, Mouthaan I, de Neef M. Diversity in sexual health: problems and dilemmas. Eur J Contracept Reprod Health Care 2005;10:207-11.

3 Rasch V, Gammeltoft T, Knudsen LB, et al. Induced abortion in Denmark: effect of socio-economic situation and country of birth. Eur J Public Health 2008;18:144-9.

4 Vangen S, Eskild A, Forsen L. Termination of pregnancy according to immigration status: a population-based registry linkage study. BJOG 2008;115:1309-15.

5 Helström L, Zätterström C, Odlind V. Abortion rate and contraceptive practices in immigrant and Swedish adolescents. J Pediatr Adolesc Gynecol 2006;19:209-13.

6 Helström L, Odlind V, Zätterström C, et al. Abortion rate and contraceptive practices in immigrant and native women in Sweden. Scand J Public Health 2003;31:405-10.

7 The National Board of Health and Welfare. Statistik om aborter 2016, 2017:4.

8 The National Board of Health and Welfare. Aborter 2008 induced abortions 2008, 2009:49.

9 Larsson M, Aneblom G, Odlind V, et al. Reasons for pregnancy termination, contraceptive habits and contraceptive failure among Swedish women requesting an early pregnancy termination. Acta Obstet Gynecol Scand 2002;81:64-71.

10 Kopp Kallner H, Thunell L, Brynhildsen J, et al. Use of contraception and attitudes towards contraceptive use in Swedish women - a nationwide survey. PLoS One 2015;10:e0125990.

11 Winner B, Peipert JF, Zhao Q, et al. Effectiveness of long-acting reversible contraception. N Engl J Med 2012;366:1998-2007.

12 Cameron ST, Glasier A, Chen ZE, et al. Effect of contraception provided at termination of pregnancy and incidence of subsequent termination of pregnancy. BJOG 2012;119:1074-80.

13 Heikinheimo O, Gissler M, Suhonen S. Age, parity, history of abortion and contraceptive choices affect the risk of repeat abortion. Contraception 2008;78:149-54.

14 United Nations. 2017 https://www.un.org/sustainabledevel opment/sustainable-development-goals/ Last accessed 16 Feb 2018

15 Public Health Agency of Sweden. 2017 https://www. folkhalsomyndigheten.se/om-folkhalsomyndigheten/ folkhalsopolitiska-mal/ Last accessed 16 Feb 2018 
16 Statistics Sweden, 2017 http://www.statistikdatabasen.scb.se Last accessed 16 Feb 2018

17 Bratlie M, Aarvold T, Skårn ES, et al. Long-acting reversible contraception for adolescents and young adults - a cross-sectional study of women and general practitioners in Oslo, Norway. Eur J Contracept Reprod Health Care 2014;19:194-202.

18 Bitzer J, Gemzell-Danielsson K, Roumen F, et al. The CHOICE study: effect of counselling on the selection of combined hormonal contraceptive methods in 11 countries. Eur J Contracept Reprod Health Care 2012;17:65-78.

19 Halpern V, Lopez LM, Grimes DA, et al. Strategies to improve adherence and acceptability of hormonal methods of contraception. Cochrane Database Syst Rev 2013;10:CD004317.

20 Secura GM, Allsworth JE, Madden T, et al. The Contraceptive CHOICE Project: reducing barriers to long-acting reversible contraception. Am J Obstet Gynecol 2010;203:115.e1-7.

21 Egarter C, Grimm C, Nouri K, et al. Contraceptive counselling and factors affecting women's contraceptive choices: results of the CHOICE study in Austria. Reprod Biomed Online 2012;24:692-7.

22 Gemzell-Danielsson K, Thunell L, Lindeberg M, et al. Comprehensive counseling about combined hormonal contraceptives changes the choice of contraceptive methods: results of the CHOICE program in Sweden. Acta Obstet Gynecol Scand 2011;90:869-77.

23 Peipert JF, Zhao Q, Allsworth JE, et al. Continuation and Satisfaction of Reversible Contraception. Obstetrics \& Gynecology 2011;117:1105-13.
24 McNicholas C, Madden T, Secura G, et al. The contraceptive CHOICE project round up: what we did and what we learned. Clin Obstet Gynecol 2014;57:635-78.

25 Swedish Medical Products Agency. Swedish national recommendations on contraceptive use. Uppsala: Swedish Medical Products Agency, 2017.

26 Larsson EC, Fried S, Essén B, et al. Equitable abortion care - a challenge for health care providers. Experiences from abortion care encounters with immigrant women in Stockholm, Sweden. Sex Reprod Healthc 2016;10:14-18.

27 Dwamena F, Holmes-Rovner M, Gaulden CM, et al. Interventions for providers to promote a patient-centred approach in clinical consultations. Cochrane Database Syst Rev 2012;12:CD003267.

28 World Values Survey W. Cultural map. 2015. http://www. worldvaluessurvey.org/WVSContents.jsp (accessed 22 Dec 2017).

29 Díez E, López MJ, Marí-Dell’Olmo M, et al. Effects of a counselling intervention to improve contraception in deprived neighbourhoods: a randomized controlled trial. Eur J Public Health 2018;28:10-15.

30 Kolak M, Jensen C, Johansson M. Midwives' experiences of providing contraception counselling to immigrant women. Sex Reprod Healthc 2017;12:100-6.

31 Ostrach B. "Yo no sabía..."-immigrant women's use of national health systems for reproductive and abortion care. J Immigr Minor Health 2013;15:262-72. 